\title{
A Pioneering Study of Retinal Pigment Epithelial Photocoagulation to Seal Retinal Breaks and Prevent Hypotony during Pars Plana Vitrectomy
}

\author{
XUN YANG ( $\square$ dryxun@163.com ) \\ https://orcid.org/0000-0003-0242-0263 \\ YOUYOU ZHA \\ lixiang eye hospital of soochow university \\ SHU DU \\ lixiang eye hospital of soochow university \\ XING CHEN \\ Wuxi No.9 Hospital Affiliated to Soochow University
}

\section{Research article}

Keywords: Retinal detachment; Retinotomy; RPE photocoagulation; ocular endoscopy, hypotony

Posted Date: March 8th, 2019

DOI: https://doi.org/10.21203/rs.2.437/v1

License: (a) (i) This work is licensed under a Creative Commons Attribution 4.0 International License. Read Full License 


\section{Abstract}

Background: During vitrectomy, a relatively high level of accuracy is required when using retinal laser energy, which is difficult to control in the presence of subretinal fluid and other conditions. We explored the clinical effects of retinal pigment epithelium

(RPE)photocoagulation in closing retinal breaks and preventing hypotony during vitrectomy. We describe the possible indications of RPE photocoagulation. Methods: This was a prospective, non-random, uncontrolled case series study. We recruited 20 patients, with retinal detachment in 20 eyes. In this study, RPE photocoagulation was performed under the detached retina and retinal holes. RPE laser photocoagulation was performed in 3-4 rows at the edge of the periphery around the hole and the tear, replacing the traditional retinal photocoagulation and closing part or all of the retinal break. The energy of RPE photocoagulation was $100-150 \mathrm{~mJ}$ for $120-200 \mathrm{~ms}$ to seal the breaks, and the same energy but little gaps for the RPE without covering of retina. Results: After vitrectomy, in 19 eyes, there was a visible pigmentation reaction around the hole and tear, except for 1 eye the retinal hole located in the myelinated nerve fibre area. The mean best-corrected visual acuity (BCVA) at 6 months after surgery was significantly higher than that before surgery $(p=0.002)$. At the last follow-up, the mean BCVA remained significantly higher than that before surgery $(p=0.001)$. There was no significant difference in BCVA between the 6th month and the last follow-up $(p=0.806)$. The thickness of the neurosensory layer in RPE photocoagulation and retinal photocoagulation area at 1 month after surgery was $216.33 \pm 54.42 \mu \mathrm{m}$ and $87.67 \pm 34.65 \mu \mathrm{m}$, respectively. By the end of the followup, there were no serious complications, and the retinas of all 20 eyes were reattached. No hypotony occurred after surgery. Conclusions: The effects of RPE photocoagulation and retinal photocoagulation are similar in closing retinal breaks. The RPE laser sealed the retinal breaks and did not damage the neurosensory layer, but still caused pigmentation formation on the RPE, resulting in adhesion between the neurosensory layer and the RPE layer. Laser photocoagulation could be considered as comparable to glue instead of welding when closing the retinal breaks. Trial registration ChiCTR1900021504,2019-02-24.

\section{Background}

Rhegmatogenous retinal detachment(RRD) is formed by liquefied vitreous entering the subretinal space through a retinal tear[1]. Closure of the retinal tear is the key to the treatment of retinal detachment. Laser can be absorbed by the melanin tissue in the fundus and the haemoglobinin the blood vessels, which produces a thermal effect. This causes the tissue to coagulate and become necrotic, forming a retinal choroidal scar adhesion, which can result in closing of the retinal tear[2-4].The method with which laser photocoagulation seals the hole is simple, resulting in a minor wound and the treatment can be repeated. Laser photocoagulation can prevent the occurrence of retinal detachment for dry holes, promote the absorption of subretinal fluid and prevent the development of lesions[5,6].

Retinal laser photocoagulation is not considered ideal in conventional vitrectomy surgery and may even cause complications in the following situations:(1)It is easy to cause iatrogenic tearing in patients with high myopia, especially in the thinner part of the peripheral retina[8].(2)Absorption of high-intensity laser energy in areas with hyperpigmentation or retinal thinning can cause damage to nerve fibres [8,9].(3) For patients with diabetic retinopathy oedema or haemorrhage, it is difficult to produce ideal results using ordinary laser methods $[10,11]$.(4) If the retinal tear is located in the middle of the myelinated nerve fibre layer, it is difficult for the laser to penetrate. (5)It is difficult to form an effective laser spot when there is subretinal fluid.

In clinical retinal reattachment surgery, a small amount of subretinal fluid residue is often found without using 'heavy liquid'(perfluorodecalin or perfluorocarbon), especially on the posterior edge of the retinal tear. It is difficult for laser spots to form on the retina. In this case, it may be necessary to increase the laser energy[12-14].Based on our clinical experience and references, we hypothesised that retinal pigment epithelial (RPE) photocoagulation is effective in patients with closed retinal tears during vitrectomy. Therefore, in this study, we reported the results and recovery of RPE photocoagulation closure of retinal breaks during vitrectomy.

\section{Methods}

Twenty patients, with 20 eyes affected by retinal detachment were enrolled; patients were diagnosed by the Lixiang Eye Hospital of Suzhou University from January 2015 to October 2017. We specifically included the eyes with subretinal fluid which was difficult to remove, or the transparency of the retina was seriously affected (e.g.intraretinal hemorrhage, severe retinal edema or myelinated nerve fibers) during surgery. The exclusion criteria for this study were the eyes with RPE photocoagulation range less than $50 \%$ around the breaks, or the eyes with good results after retinal photocoagulation. The follow-up time was 11-33months, and the average follow-up time was $(22.1 \pm 8.0)$ months. This study complies with the Hospital Ethics Committee and the World Helsinki Declaration. Informed consent was signed for each patient prior to their recruitment to this study. All patients underwent a comprehensive eye exam including non-contact intraocular pressure(IOP), best corrected visual acuity (BCVA), slit lamp, B-ultrasound and fundus examination. 
Twenty patients underwent vitrectomy, retinal reattachment, gas-liquid exchange, gas filling or silicone oil filling, with11 patients undergoing retinotomy.

The postoperative follow-up time was scheduled for 1 week, 1 month, 3 months, 6 months and 1 year after surgery. At each follow-up visit, the best corrected visual acuity, anterior segment and intraocular pressure examination were performed. After fully dilating the pupils, the patient's fundus was observed with a +90.0D anterior lens, and binocular indirect ophthalmoscopy was performed. When necessary, optical coherence tomography(OCT,Stratus; ZEISS; Germany) and fundus photography were used to record postoperative fundus recovery and postoperative complications. All Snellen visual acuity was converted to logarithm of the minimum angle of resolution (LogMAR) for statistical analysis. The counting fingers in visual acuity are defined as 2.3logMAR, the hand movements are 2.6logMAR, and the light perception is $2.9 \log M A R$.

Surgical procedure

All procedures were performed by the same doctor (X.Y). After the patient was subjected to retrobulbar anaesthesia or general anaesthesia, a three-port closed vitrectomy was used to completely remove the vitreous with a surgical microscope or ocular endoscope. The proliferating membrane, vitreous traction membrane and part of the neovascular membrane were removed,whilst minimising mechanical retraction, the retina was loosened, and if necessary the 'heavy liquid' was used to reattach the retina. Retinotomy or resection was performed on areas with severely fixed folds, retinal stiffness, or shortened, thickened or curled areas that could not be flattened. The extent of retinotomy was dependent on the size of the lesion and varied in this group from $45^{\circ}$ to $220^{\circ}$.In this study, 11 patients underwent retinotomy, and RPE photocoagulation was performed at the posterior margin of the retinal break. One patient with retinal detachment had a myelinated nerve fibre on the edge of the optic disc, and the hole was located in the middle of it, and RPE photocoagulation was performed under the detached retina.RPE laser photocoagulation was performed in 3-4 rows at the peripheral edge around the hole and the tear, resulting in partial or complete closure and replacing the traditional retinal laser photocoagulation. Partial RPE laser range refers to $\geq 180^{\circ}$ circumference. The remainder of the range is performed by conventional retinal photocoagulation. The energy of RPE photocoagulation was $100-150 \mathrm{~mJ}$ for $120-200 \mathrm{~ms}$. The light spot reaction on the RPE results in shows a paler yellow colour compared to the reaction when laser is not used. An attempt was made to avoid the occurrence of bubbles or blasting during the operation. After gas-liquid exchange or heavy liquid use, the hole was observed during retinal reattachment, and the pale yellow RPE laser area could still be seen through the retina. If the RPE laser near the edge of the hole was insufficient due to the displacement of the hole, the conventional retinal laser was used to supplement treatment. In this study, RPE photocoagulation in case 19 was performed under endoscopy-assisted vitrectomy. After the operation, the vitreous cavity was filled with silicone oil or gas (C3F8 or SF6). The light spot reaction on the RPE results in shows a paler yellow colour compared to the reaction when laser is not used. Patients who underwent silicone oil injection had silicone oil removal 3 to 6 months after the operation.

Additionally, following retinal reattachment in the retinotomy, if necessary, the pigment epithelial layer exposed to the incision zone was also photocoagulated using a dense spot with the same energy and little gaps. The continuous photocoagulation can be applied to the wider area, so that the pigment epithelial layer is completely covered by photocoagulation.

Statistical analysis

We used SPSS 17.0 statistical software (IBM/SPSS, Inc., Chicago IL) for statistical nonparametric analysis. Visual acuity, intraocular pressure, and thickness of the neurosensory layer were expressed as mean \pm standard deviation in all continuity data. A P-value of less than 0.05 was considered statistically significant.

\section{Results}

There were 20 patients with 20 affected eyes in this study, including 12 males and 8 females, average age $47.4 \pm 15.0$ years (range, 2469 years). The basic characteristics of the statistical data for all patients are listed in Table 1. 
There were 11 eyes with rhegmatogenous retinal detachment(cases 1,2,4,7,8,9,12,13,14,17 and 20), including 3 eyes with macular holes and rhegmatogenous retinal detachment(cases 14,17 and 20), 2 eyes with recurrent retinal detachment(cases 16 and 18), 4 eyes with long-standing retinal detachment(case3,6,15 and 19), and 1 eye with traction retinal detachment caused by diabetic retinopathy(case11).In this study, 2 patients with recurrent retinal detachment were found to have severe retinal proliferation during surgery, and retinotomy was performed concurrently. In the patient with traction retinal detachment caused by diabetic retinopathy,RPE photocoagulation was performed; a retinal tear occurred while the proliferative membrane was being removed.Among the 11 patients with retinotomy, 6 patients had high myopia, 2 patients had moderate myopia, 1 patient had mild myopia, 1 patient had proliferative vitreoretinopathy(PVR) and 1 patient had myelinated nerve fibres near the optic disc. There were preoperative giant breaks in 5 of the eyes. All twenty patients had no other retinal reattachment operation after surgery, except silicone oil removal. The average IOP of these 11 eyes was $14.8 \pm 2.9$ (range9.1-18.5) $\mathrm{mmHg}$ at 6 months after surgery, statistically different from the IOP before surgery $11.4 \pm 2.1$ (range8.5-14.1) $\mathrm{mmHg}(\mathrm{p}=0.000)$.

After vitrectomy, in 19 eyes, there was a visible pigmentation reaction around the hole and tear, except for 1 eye the retinal hole located in the myelinated nerve fibre area, and the pigmentation reaction can only partially be seen.

The patient's IOP before surgery was 11.3 \pm 2.4 (range7.2-15.1) $\mathrm{mmHg}$. At 6 months after surgery, the average IOP of 18 eyes was $18.2 \pm 3.1 \mathrm{mmHg}$ (range $9.1 \otimes 22.0$ ) mmHg. Hydrochloride or Brinzolamidetimolol effectively controlled the high IOP in the other two eyes. The preoperative average LogMARBCVA was 1.60 (Snellen equivalent 20/800), and the range was: light perception 20/20.At 6 months postoperatively, the mean LogMAR BCVA was 0.56 (Snellen equivalent 20/63) and at the last follow-up it was 0.53 (20/63). The main changes in the vision before and after Pars plana vitrectomy (PPV) are shown in Figure 1.

The mean BCVA at 6 months after surgery was significantly higher than that before surgery $(p=0.002)$. At the last follow-up, the mean BCVA was significantly higher than that before surgery $(p=0.001)$. There was no statistically significant difference between BCVA at 6 months postoperatively and at the last follow-up $(p=0.806)$.

In 3patients, neurosensory thickness was measured after RPE photocoagulation and retinal photocoagulation surgery. At 1 month after surgery, the thickness of the neurosensory layer after RPE photocoagulation was $181 \mu \mathrm{m}$ (case 14), $189 \mu \mathrm{m}$ (case 17), and $286 \mu \mathrm{m}$ (case 20); the average thickness was $216.33 \pm 54.42 \mu \mathrm{m}$. The thickness of the neurosensory layer of the retinal photocoagulation area was $55 \mu \mathrm{m}, 124 \mu \mathrm{m}$ and $76 \mu \mathrm{m}$, respectively. The average thickness was $87.67 \pm 34.65 \mu \mathrm{m}$ (Figure 2D; 2E; 4A, 4B).After RPE photocoagulation, the pigment was gradually increased in the RPE photocoagulation area (Figure $2 \mathrm{~B} ; 2 \mathrm{C}$ ). In all the eyes, there was a visible pigmentation reaction in the holes and tears, including one eye with a retinal hole located in the myelinated nerve fibres(Figure 3 ).

Severe postoperative complications, such as endophthalmitis or recurrent retinal detachment, did not occur in any eye. Haemorrhage at the retinal incision gradually disappeared within 1 month after the initial follow-up. Silicone oil emulsification was observed in 4 eyes throughout the follow-up period. After removing silicone oil from eyes in which silicone oil was used, the retinal reattachment success rate reached $100 \%$.

\section{Discussion}

In clinical treatment, laser can be directly applied to the retina on the marginof the retinal tear to form white photocoagulation spots. Retinal pigment epithelial cells (RPE) and choroidal melanocytes can absorb most of the laser energy, and coagulation necrosis initially occurs. When the laser energy is low, only RPE cells and mitochondria are swollen, the endoplasmic reticulum expands, the villi are reduced, tight junctions between cells are destroyed, a small proportion of RPE cells are necrotic and the choroidal hair cells are swollen[2,5,15].As the laser energy increases, the energy absorbed by the RPE cells increases, and the range of thermal effects increases. As a result, the cell damage is aggravated, the RPE cells are lysed and destroyed, and the heat is transmitted to the nearby nerve retina, causing damage to some of the outer retinal cells[14,15]. The laser can destroy the pigment epithelial tissue and cause the increase of cell growth factor, and also promote the cell proliferation and repair. The RPE proliferation around the photocoagulation zone covers the destruction zone, and the proliferating RPE cells have less pigmentation and fewer tight junctions between cells[1619].The energy range of RPE photocoagulation is $100-150 \mathrm{~mJ}$.In this study, the thickness of the neurosensory layer under RPE photocoagulation and retinal photocoagulation was $216.33 \pm 54.42 \mu \mathrm{m}$ and $87.67 \pm 34.65 \mu \mathrm{m}$, respectively, 1 month after surgery. We can initially propose that the RPEphotocoagulation is less destructive to the retinal neurosensory layer.

The surgical innovations and theories of rhegmatogenous retinal detachment are still under discussion. In all the eyes in this study, there was a visible pigmentation reaction at the holes and tears after surgery. We believe that RPE photocoagulation has a similar 
sealingeffect of reattaching the retina, bonding the two sides like glue. Heriot WJ indicates that thermal fusion of the retina with the RPE at the margin of a retinal tear by laser can be undertaken by first removing the subretinal fluid prior to photocoagulation[20].The integrated coagulum seals the tear margin preventing further fluid entering the subretinal space, thus correcting the cause of rhegmatogenous retinal detachment(RRD). Yamana T, et al. indicated that glial and RPE cells might play an important role in closure of a retinal hole between the sensory retina and RPE[21].

In many cases, during retinal detachment surgery, retinotomy promotes a significant increase in the success of retinal reattachment. For example, cases of RRD[20] with high myopia and a marked increase in the axial length[22,23], retinal detachment with severe proliferative vitreoretinopathy (PVR) $[24,25]$ or a giant tear. In cases of ocular trauma, the majority of patients are young and middleaged, and the vitreous proliferation of the injured eye is often very intense. In order to loosen the severe traction, especially the peripheral traction, extensive retinotomy is required[26-28]. Our innovative surgical approach to RPE photocoagulation was first applied in endoscopic-assisted vitrectomy, such as in case 19.In the cases with severe retinal oedema and bleeding, conventional retinal photocoagulation is difficult to perform, however endoscope assisted RPE photocoagulation is clear and simple.Part of the pigment epithelial layer is exposed in retinotomy and retinectomy, which leads to an increase in intraocular fluid outflow and a postoperative chronichypotony. During the operation, photocoagulation of the pigment epithelial exposed area and coagulative necrosis of the pigment epithelial cells eventually cause scarring, thereby reducing the choroidal outflow of the intraocular fluid. To a certain extent, the stability of the intraocular pressure is maintained, and the occurrence of hypotony is prevented[29].Chronic hypotony did not occur in this study series. From this study, it was determined that RPE photocoagulation can be performed as necessary during surgery. Pigment epithelial photocoagulation has an irreplaceable advantage in certain cases. This procedure may also reduce the migration and evolution of pigment epithelial cells to a considerable extent, reducing the chances of PVR development [30-34].

In this study, the visual acuity of patients at 6 months after surgery was significantly higher than that before surgery. After 6 months, there was no significant further improvement in visual acuity. The postoperative retinal reattachment rate was $100 \%$. There are many possible advantages of RPE photocoagulation to seal retinal breaks including: (1)The process does not generate heat on the inner 9 layers of the retina, and does not cause atrophic retinal holes. (2)When a neurosensory opacity or oedema is present, all energy can reach the RPE, without increasing the laser energy, whilst protecting the neurosensory layer. (3) Provides sufficient energy to the RPE layer when there is intraretinal haemorrhage or if the myelinated nerve fibre layer is covered. (4) Does not cause contraction of the retina. (5) It seems to have a greater therapeutic window for laser energy.

\section{Limitations}

RPE photocoagulation damages the function of the retinal epithelial layer, without the observation of electroretinogram, or fundus fluorescence angiography and other imaging techniques. The number of cases is limited and the fundus data of follow-up OCT examination is very limited. Furthermore, the position of the retina may change during the reattachment of the retina. Sometimes the estimated deviation is large, and some retinal photocoagulation is needed after retinal reattachment. A further study is needed to establish if there is a difference in the strength of scar connection between the retina and the choroid after RPE photocoagulation or retinal photocoagulation.

\section{Conclusions}

In summary, this study showed that retinal RPE layer photocoagulation is similar in sealing retinal holes and tears in the treatment of retinal detachment, and the use of RPE photocoagulation (including combined with conventional retinal photocoagulation) can reduce the difficulty of the procedure and cause minimal damage to the neurosensory layer. Laser photocoagulation may be considered to be analogous to glue rather than welding when closing retinal breaks. RPE photocoagulation on areas not covered by the retina causes scar formation in the RPE layer, resulting in the prevention of hypotony after retinotomy or retinectomy

\section{Abbreviations}

BCVABest-corrected visual acuity

DRDiabetic retinopathy

FFemale

FCFinger counting 
HIMHigh myopia

HMHand movements

IOP Intraocular pressure

IVIIntravitreal injection

LogMARLogarithm of the minimum angle of resolution

LPLight perception

LRDLong-standing retinal detachment

MMale

MHMacular hole

NNone

OCTOptical coherence tomography

ODRight eye

OSLeft eye

PPVPars plana vitrectomy

PVRProliferative vitreoretinopathy

ReRDRecurrent retinal detachment

RPERetinal pigment epithelium

RRDRhegmatogenous retinal detachment

TRDTraction retinal detachment

VHVitreous haemorrhage

yYear

\section{Declarations}

\section{Ethics approval and consent to participate}

The study was approved by the LiXiang Eye Hospital of Soochow University Committee for Research Ethics, and was conducted in accordance with the official regulations for clinical research and the Declaration of Helsinki. We have obtained signed informed consent for participation in this study and consent to publish from each participant to report individual patient data.

\section{Consent for publication:}

Not Applicable.

\section{Availability of data and materials}

Data are available upon request due to concerns about potential breach of confidentiality. The dataset is only available upon request to qualified researchers. Please contact the first author, $X Y$, for access to the data set. 
The authors declare no conflict of interest.

\section{Funding}

Not Applicable.

\section{Author Contributions}

$\mathrm{XY}$ designed the study and performed the operation. YYZ, SD collected the data and assisted the operations; $Y Y Z$ and $X C$ analyzed the data. XC drafted the paper; $\mathrm{XY}$ contributed to the revision of the paper. All authors have read and approved the manuscript.

\section{Acknowledgements}

Not Applicable.

\section{References}

1. Feltgen N, Walter P. Rhegmatogenous retinal detachment-an ophthalmologic emergency. Dtsch Arztebl Int. 2014;111:12-21.

2.YoonYH, Marmor MF. Rapid enhancement of retinal adhesion by laser photocoagulation.

Ophthalmology. 1988;95:1385-8.

3.KainHL. Chorioretinal adhesion after argon laser photocoagulation.ArchOphthalmol.

$1984 ; 102: 612-5$.

4.Folk JC, Sneed SR, Folberg R, CoonanP, Pulido JS. Early retinal adhension from laser photocoagulation.Ophthalmology.1989;96:15235.

5.Curtin VT, Norton EW, Gass JD. Photocoagulation:its use in the prevention of reoperation after scleral buckling operations. Trans Am Acad Ophthalmol Otolaryngol. 1967;71: 432-41.

6.DelaneyWJ,Torrisi PF, HamptonGR,SeigartCR,Hay PB. Photocoagulation using the Eisner cone. Retina. 1989;9:22-7.

7. Frayer WC. Reactivity of the retinal pigment epithelium: an experimental and histopathologic study. Trans Am Ophthalmol Soc. 1966; 64: 586-643.

8.Tsai CY, Hung KC,Wang SW,Chen MS,Ho TC.Spectral-domain optical coherence tomography of peripheral lattice degeneration of myopic eyes before and after laser photocoagulation. (2018), https://doi.org/10.1016/ j.jfma.2018.08.005.

9.Lawwill T. Three major pathologic processes caused by light in the primate retina: a search for mechanisms. Trans Am Ophthalmol Soc. 1982;80:517-79.

10.Romero-Aroca P, Reyes-Torres J, Baget-Bernaldiz M,Blasco-Suñe C. Laser Treatment for Diabetic Macular Edema in the 21st Century.CurrDiabetes Rev. 2014; 10:100-112.

11.LuttrullJK,DorinG.Subthreshold Diode Micropulse Laser Photocoagulation (SDM) as Invisible Retinal Phototherapy for Diabetic Macular Edema: A Review.Curr Diabetes Rev. 2012 ;8:274-84.

12. Kozakl,LuttrullJK.Modern retinal laser therapy.Saudi J Ophthalmol. 2015; 29:137-46.

13.Yadav NK, Jayadev C, RajendranA, NagpaIM. Recent developments in retinal lasers and delivery systems. Indian J Ophthalmol. 2014; 62:50-4.

14.Foster WJ.Vitreous Substitutes. Expert Rev Ophthalmol. 2008 ;3:211-18.

15. Roider J, Brinkmann R,Wirbelauer C, Laqua H, Birngruber R. Retinal sparing by selective retinal pigment epithelial photocoagulation. Arch Ophthalmol. 1999; 117:1028-34. 
16.Bhuttol,Lutty G. Understanding age-related macular degeneration (AMD): Relationships between the photoreceptor/retinal pigmentepithelium/Bruch's membrane /choriocapillaris complex. Mol Aspects Med.2012;33:295-317.

17.GuymerRH,HagemanGS, Bird AC. Influence of laser photocoagulation on choroidal capillary cytoarchitecture. $\mathrm{Br}$ JOphthalmol. 2001; 85: 40-46

18.PollackA,Korte GE, Heriot WJ, Henkind P, HenkindP. Ultrastructure of Bruch's membrane after krypton laser photocoagulation. II. Repair of Bruch's membrane and the role of macrophages. Arch Ophthalmol. 1986;104:1377-82.

19.Roider J, Michaud NA, Flotte TJ, BirngruberR.Response of the retinal pigment epithelium to selective photocoagulation.Arch Ophthalmol. $1992 ; 110: 1786-92$.

20.HeriotWJ.Thermofusion of the retina with the RPE to seal tears during retinal detachment repair.Graefes Arch Clin Exp Ophthalmol. 2016;254:691-6

21.Yamana T, Kita M, Ozaki S, Negi A.; Honda Y.The process of closure of experimental retinal holes in rabbit eyes.Graefes Arch Clin Exp Ophthalmol. 2000;238:81-7.

22. Coppola M,Rabiolo A,Cicinelli MV,Querques G,Bandello F.Francesco Bandello Vitrectomy in high myopia: a narrative review. Int J Retina Vitreous. 2017;3:37.

23. Jeon HS, Byon IS, Park SW, LeeJE, Oum BS. Extramacular drainage of subretinal fluid during vitrectomy for macular hole retinal detachmentin high myopia.Retina.

2014;34:1096-102.

24. Kimura M,NishimuraA,SaitoY,IkedaH,SugiyamaK.Retinotomy with retinal turnover to remove subretinal membranes under direct visualization for proliferative vitreoretinopathy. ClinOphthalmol. 2012; 6 :781-8.

25.Mendes TS, Gomes AMV, Rocha BS, Passos Junior HV, Abujamra S. Evaluation of retinectomy in the treatment of severe proliferative vitreoretinopathy.Int J Retina Vitreous. 2015;1: 17.

26.Shalaby KA.Relaxing retinotomies and retinectomies in the management of retinal detachment with severe proliferative vitreoretinopathy(PVR).Clin Ophthalmol. 2010;4: 1107-14.

27.Bovey EH, De AncosE,GonversM. Retinotomies of 180 degrees or more. Retina.

1995;15:394-8.

28.Tsui I,Schubert HD. Retinotomy and silicone oil for detachments complicated by anterior inferior proliferative vitreoretinopathy. $\mathrm{Br} \mathrm{J}$ Ophthalmol. $2009 ; 93: 1228-33$.

29. Yang X, Ren H, Du S; Tang HX. The Effect of Photocoagulation of Retinal Pigment Epithelium on the Intraocular Pressure of Hypotonic Rabbit Eyes Due to Retinal Defect .Ophthalmologica. 2014;232:81.

30.Nagasaki H, Shinagawa K,Mochizuki, M. Risk factors for proliferative vitreoretinopathy.

Prog Retin Eye Res. $1998 ; 17: 77-98$.

31.Kwon OW,Song JH,Roh MI. Retinal Detachment and Proliferative Vitreoretinopathy.

Dev Ophthalmol. 2016;55:154-62.

32.Khoroshilova-MaslovalP,Leparskaya NL ,Vorotelyak EA,Vasiliev AV. The significance of fibroblasts in experimental modeling of proliferative vitreoretinopathy.

VestnOftalmol. 2017;133:4-10.

33.TamiyaS,KaplanHJ. Role of epithelial-mesenchymal transition in proliferative vitreoretinopathy. Exp Eye Res. 2016 ;142:26-31. 
34.Feist RM Jr,King JL,Morris R,Witherspoon CD,Guidry C. Myofibroblast and extracellular matrix origins in proliferative vitreoretinopathy.Graefes Arch Clin Exp Ophthalmol.

$2014 ; 252: 347-57$.

1. Feltgen N, Walter P. Rhegmatogenous retinal detachment-an ophthalmologic emergency. Dtsch Arztebl Int. 2014;111:12-21.

2.YoonYH, Marmor MF. Rapid enhancement of retinal adhesion by laser photocoagulation.

Ophthalmology. 1988;95:1385-8.

3.KainHL. Chorioretinal adhesion after argon laser photocoagulation.ArchOphthalmol.

$1984 ; 102: 612-5$.

4.Folk JC, Sneed SR, Folberg R, CoonanP, Pulido JS. Early retinal adhension from laser photocoagulation.Ophthalmology.1989;96:15235.

5.Curtin VT, Norton EW, Gass JD. Photocoagulation:its use in the prevention of reoperation after scleral buckling operations. Trans Am Acad Ophthalmol Otolaryngol. 1967;71: 432-41.

6.DelaneyWJ,Torrisi PF, HamptonGR,SeigartCR,Hay PB. Photocoagulation using the Eisner cone. Retina. 1989;9:22-7.

7. Frayer WC. Reactivity of the retinal pigment epithelium: an experimental and histopathologic study. Trans Am Ophthalmol Soc. 1966; 64: 586-643.

8.Tsai CY, Hung KC,Wang SW,Chen MS,Ho TC.Spectral-domain optical coherence tomography of peripheral lattice degeneration of myopic eyes before and after laser photocoagulation. (2018), https://doi.org/10.1016/ j.jfma.2018.08.005.

9.Lawwill T. Three major pathologic processes caused by light in the primate retina: a search for mechanisms. Trans Am Ophthalmol Soc. 1982;80:517-79.

10.Romero-Aroca P, Reyes-Torres J, Baget-Bernaldiz M,Blasco-Suñe C. Laser Treatment for Diabetic Macular Edema in the 21st Century.CurrDiabetes Rev. 2014; 10:100-112.

11.LuttrullJK,DorinG.Subthreshold Diode Micropulse Laser Photocoagulation (SDM) as Invisible Retinal Phototherapy for Diabetic Macular Edema: A Review.Curr Diabetes Rev. 2012 ;8:274-84.

12. Kozakl,LuttrullJK.Modern retinal laser therapy.Saudi J Ophthalmol. 2015; 29:137-46.

13.Yadav NK, Jayadev C, RajendranA, NagpaIM. Recent developments in retinal lasers and delivery systems. Indian J Ophthalmol. 2014; 62:50-4.

14.Foster WJ.Vitreous Substitutes. Expert Rev Ophthalmol. 2008 ;3:211-18.

15. Roider J, Brinkmann R,Wirbelauer C, Laqua H, Birngruber R. Retinal sparing by

selective retinal pigment epithelial photocoagulation. Arch Ophthalmol. 1999; 117:1028-34.

16.Bhuttol,Lutty G. Understanding age-related macular degeneration (AMD): Relationships between the photoreceptor/retinal pigmentepithelium/Bruch's membrane /choriocapillaris complex. Mol Aspects Med.2012;33:295-317.

17.GuymerRH,HagemanGS, Bird AC. Influence of laser photocoagulation on choroidal capillary cytoarchitecture. $\mathrm{Br}$ JOphthalmol. 2001; 85: 40-46

18.PollackA,Korte GE, Heriot WJ, Henkind P, HenkindP. Ultrastructure of Bruch's membrane after krypton laser photocoagulation. II. Repair of Bruch's membrane and the role of macrophages. Arch Ophthalmol. 1986;104:1377-82. 
19.Roider J, Michaud NA, Flotte TJ, BirngruberR.Response of the retinal pigment epithelium to selective photocoagulation.Arch Ophthalmol. $1992 ; 110: 1786-92$.

20.HeriotWJ.Thermofusion of the retina with the RPE to seal tears during retinal detachment repair.Graefes Arch Clin Exp Ophthalmol. 2016;254:691-6

21.Yamana T, Kita M, Ozaki S, Negi A.; Honda Y.The process of closure of experimental retinal holes in rabbit eyes.Graefes Arch Clin Exp Ophthalmol. 2000;238:81-7.

22. Coppola M,Rabiolo A,Cicinelli MV,Querques G,Bandello F.Francesco Bandello Vitrectomy in high myopia: a narrative review. Int $J$ Retina Vitreous. 2017;3:37.

23. Jeon HS, Byon IS, Park SW, LeeJE, Oum BS. Extramacular drainage of subretinal fluid during vitrectomy for macular hole retinal detachmentin high myopia.Retina.

2014;34:1096-102.

24. Kimura M,NishimuraA,SaitoY,IkedaH,SugiyamaK.Retinotomy with retinal turnover to remove subretinal membranes under direct visualization for proliferative vitreoretinopathy. ClinOphthalmol. 2012; 6 :781-8.

25.Mendes TS, Gomes AMV, Rocha BS, Passos Junior HV, Abujamra S. Evaluation of retinectomy in the treatment of severe proliferative vitreoretinopathy.Int J Retina Vitreous. 2015;1: 17.

26.Shalaby KA.Relaxing retinotomies and retinectomies in the management of retinal detachment with severe proliferative vitreoretinopathy(PVR).Clin Ophthalmol. 2010;4: 1107-14.

27.Bovey EH, De AncosE,GonversM. Retinotomies of 180 degrees or more. Retina.

1995;15:394-8.

28.Tsui I,Schubert HD. Retinotomy and silicone oil for detachments complicated by anterior inferior proliferative vitreoretinopathy. Br J Ophthalmol. $2009 ; 93: 1228-33$.

29. Yang X, Ren H, Du S; Tang HX. The Effect of Photocoagulation of Retinal Pigment Epithelium on the Intraocular Pressure of Hypotonic Rabbit Eyes Due to Retinal Defect .Ophthalmologica. 2014;232:81.

30.Nagasaki H, Shinagawa K,Mochizuki, M. Risk factors for proliferative vitreoretinopathy.

Prog Retin Eye Res. 1998 ;17:77-98.

31.Kwon OW,Song JH,Roh MI. Retinal Detachment and Proliferative Vitreoretinopathy.

Dev Ophthalmol. 2016;55:154-62.

32.Khoroshilova-MaslovaIP,Leparskaya NL ,Vorotelyak EA,Vasiliev AV. The significance of fibroblasts in experimental modeling of proliferative vitreoretinopathy.

VestnOftalmol. 2017;133:4-10.

33.TamiyaS,KaplanHJ. Role of epithelial-mesenchymal transition in proliferative vitreoretinopathy. Exp Eye Res. 2016 ;142:26-31.

34.Feist RM Jr,King JL,Morris R,Witherspoon CD,Guidry C. Myofibroblast and extracellular matrix origins in proliferative vitreoretinopathy.Graefes Arch Clin Exp Ophthalmol.

$2014 ; 252: 347-57$

\section{Tables}

Table 1. Basic Characteristics of Patients $(n=20)$ With Retinal Detachment. 


\begin{tabular}{|c|c|c|c|c|c|c|c|c|c|c|c|}
\hline \multirow[t]{3}{*}{ No } & \multirow[t]{3}{*}{ Sex } & \multirow{3}{*}{$\begin{array}{l}\text { Age } \\
\square y \square\end{array}$} & \multirow[t]{3}{*}{ Eye } & \multirow{3}{*}{$\begin{array}{l}\text { Principal } \\
\text { Diagnosis }\end{array}$} & \multirow{3}{*}{$\begin{array}{l}\text { Main } \\
\text { Characteristics } \\
\text { (hole/tear) }\end{array}$} & \multirow{3}{*}{$\begin{array}{l}\text { Previous } \\
\text { Treatments }\end{array}$} & \multirow{3}{*}{$\begin{array}{l}\text { Introocular } \\
\text { Tamponades }\end{array}$} & \multirow{3}{*}{$\begin{array}{l}\text { Preoperative } \\
\text { LogMAR } \\
\text { BCVA }\end{array}$} & \multirow{3}{*}{$\begin{array}{l}\text { Preoperative } \\
\text { Snellen } \\
\text { BCVA }\end{array}$} & \multirow{3}{*}{$\begin{array}{l}\text { Final } \\
\text { Log } \\
\text { MAR } \\
\text { BCVA } \\
\end{array}$} & \multirow{3}{*}{$\begin{array}{l}\text { Final } \\
\text { Snellen } \\
\text { BCVA }\end{array}$} \\
\hline & & & & & & & & & & & \\
\hline & & & & & & & & & & & \\
\hline 1 & $\mathrm{~F}$ & 24 & OD & RRD & $\begin{array}{l}\text { Rounded }[ \\
\text { medullated } \\
\text { fibres } \square \\
\text { Retinotomy }\end{array}$ & $\mathrm{N}$ & C3F8 & 0.40 & 0.40 & 0.00 & $20 / 20$ \\
\hline 2 & $\mathrm{~F}$ & 32 & OS & RRD;Myopia & Retinotomy & $\mathrm{N}$ & C3F8 & 2.30 & $\mathrm{FC} / 10 \mathrm{~cm}$ & 1.50 & $20 / 667$ \\
\hline 3 & $\mathrm{~F}$ & 44 & OD & LRD;HIM & Retinotomy & $\mathrm{N}$ & Silicone Oil & 2.90 & LP & 2.30 & $\mathrm{FC} / 30 \mathrm{~cm}$ \\
\hline 4 & M & 35 & OD & RRD;HIM & $\begin{array}{l}\text { Giant retinal } \\
\text { tear }\end{array}$ & $\mathrm{N}$ & SF6 & 0.50 & $20 / 63$ & 0.30 & $20 / 4$ \\
\hline 5 & M & 59 & OS & $\mathrm{VH}$ & $\begin{array}{l}\text { Giant retinal } \\
\text { tear }\end{array}$ & $\mathrm{N}$ & SF6 & 2.60 & $\mathrm{HM} / 40 \mathrm{~cm}$ & 0.30 & $20 / 40$ \\
\hline 6 & $\mathrm{~F}$ & 66 & OD & LRD & Rounded & $\mathrm{N}$ & Silicone Oil & 2.60 & $\mathrm{HM} / 10 \mathrm{~cm}$ & 0.20 & $20 / 32$ \\
\hline 7 & M & 52 & OD & RRD & $\begin{array}{l}\text { Giant retinal } \\
\text { tear }\end{array}$ & $\mathrm{N}$ & SF6 & 0.00 & $20 / 20$ & 0.00 & $20 / 20$ \\
\hline 8 & M & 31 & OD & RRD & Retinotomy & $\mathrm{N}$ & C3F8 & 1.60 & $20 / 800$ & 0.10 & $20 / 25$ \\
\hline 9 & M & 45 & OD & RRD & $\begin{array}{l}\text { Giant retinal } \\
\text { tear }\end{array}$ & $\mathrm{N}$ & SF6 & 0.60 & $20 / 80$ & 0.20 & $20 / 32$ \\
\hline 10 & $\mathrm{~F}$ & 57 & OD & PVR & Retinotomy & $\mathrm{N}$ & Silicone Oil & 2.60 & $\mathrm{HM} / 10 \mathrm{~cm}$ & 1.10 & $20 / 250$ \\
\hline 11 & M & 40 & OD & DR;TRD & $\begin{array}{l}\text { Intraoperative } \\
\text { iatrogenic } \\
\text { retinal breaks }\end{array}$ & IVI & Silicone Oil & 2.60 & $\mathrm{HM} / 10 \mathrm{~cm}$ & 0.70 & $20 / 100$ \\
\hline 12 & M & 57 & OS & RRD;HIM & rounded & $\mathrm{N}$ & C3F8 & 0.10 & $20 / 25$ & 0.70 & $20 / 100$ \\
\hline 13 & M & 68 & OD & RRD & $\begin{array}{l}\text { Giant retinal } \\
\text { tear }\end{array}$ & $\mathrm{N}$ & Silicone Oil & 2.30 & $\mathrm{FC} / 50 \mathrm{~cm}$ & 0.30 & $20 / 40$ \\
\hline 14 & $\mathrm{~F}$ & 63 & OD & RRD;MH;HIM & Retinotomy & $\mathrm{N}$ & Silicone Oil & 2.60 & $\mathrm{HM} / 50 \mathrm{~cm}$ & 1.00 & $20 / 200$ \\
\hline 15 & M & 37 & OD & LRD;HIM & Retinotomy & $\mathrm{N}$ & Air & 2.30 & $\mathrm{FC} / 30 \mathrm{~cm}$ & 0.00 & $20 / 20$ \\
\hline 16 & $\mathrm{~F}$ & 27 & OS & ReRD;HIM & Retinotomy & PPV & Silicone Oil & 1.70 & $20 / 1000$ & 0.20 & $20 / 32$ \\
\hline 17 & $\mathrm{~F}$ & 53 & OD & RRD;HIM;MH & Retinotomy & PPV & Silicone Oil & 1.20 & $20 / 333$ & 0.50 & $20 / 63$ \\
\hline 18 & M & 27 & OS & ReRD;Myopia & Retinotomy & PPV & Silicone Oil & 0.40 & $20 / 50$ & 0.20 & $20 / 32$ \\
\hline 19 & M & 69 & OS & VH;Oculartrauma;LRD & Rounded & $\mathrm{N}$ & Silicone Oil & 2.90 & LP & 2.3 & $\mathrm{FC} / 30 \mathrm{~cm}$ \\
\hline 20 & $\mathrm{M}$ & 62 & OD & RRD;MH;HIM & Retinotomy & $\mathrm{N}$ & Silicone Oil & 1.3 & $20 / 400$ & 1.0 & $20 / 200$ \\
\hline
\end{tabular}

Patient demographics, diagnosis and treatment history of the 20 patients enrolled in the study. Abbreviations used: DR,diabetic retinopathy; F,female; FC,finger counting; HIM, high myopia; HM,hand movements; IVI,intravitreal injection; LP,light perception; LRD,long-standing retinal detachment; MH,macular hole; M,male; N,none; OD,right eye; OS,left eye; PPV,parsplana vitrectomy; PVR,proliferativevitreoretinopathy; ReRD,recurrent retinal detachment; TRD,traction retinal detachment; VH,vitreous haemorrhage; y, year

\section{Figures}

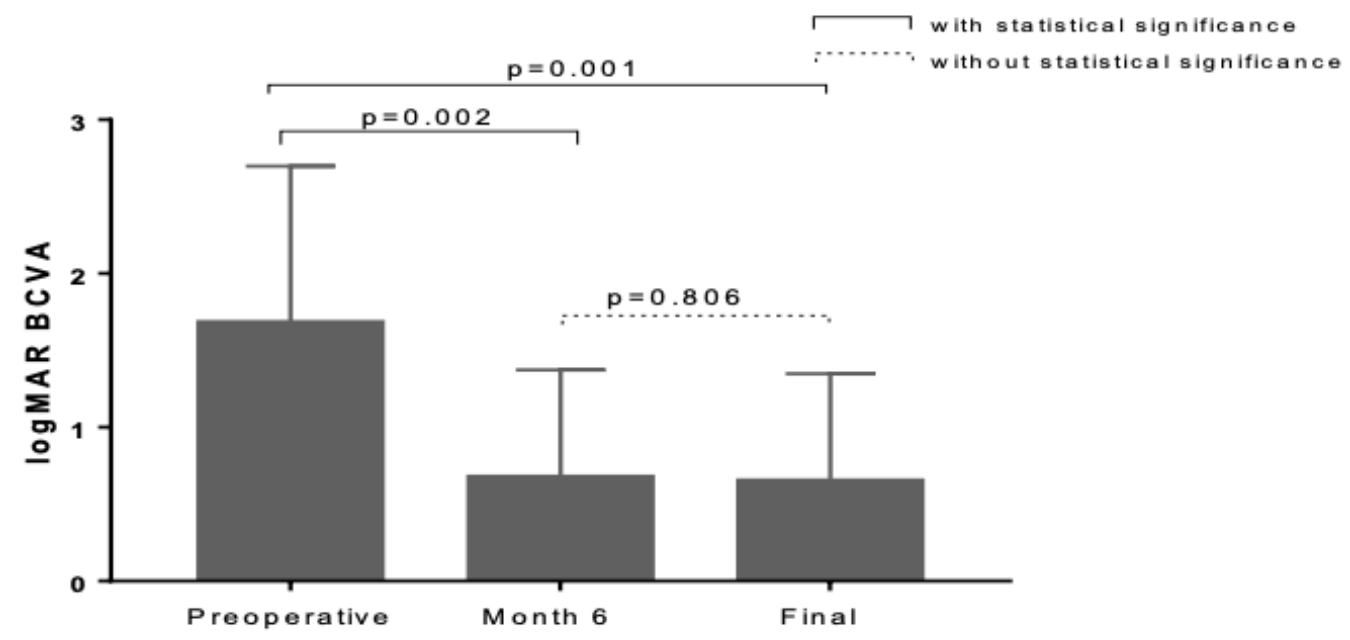




\section{Figure 1}

The graph shows changes in the vision of patients before and after PPV. Postoperative visual acuity was significantly improved compared with preoperative. There was no significant change in visual acuity during postoperative follow-up.
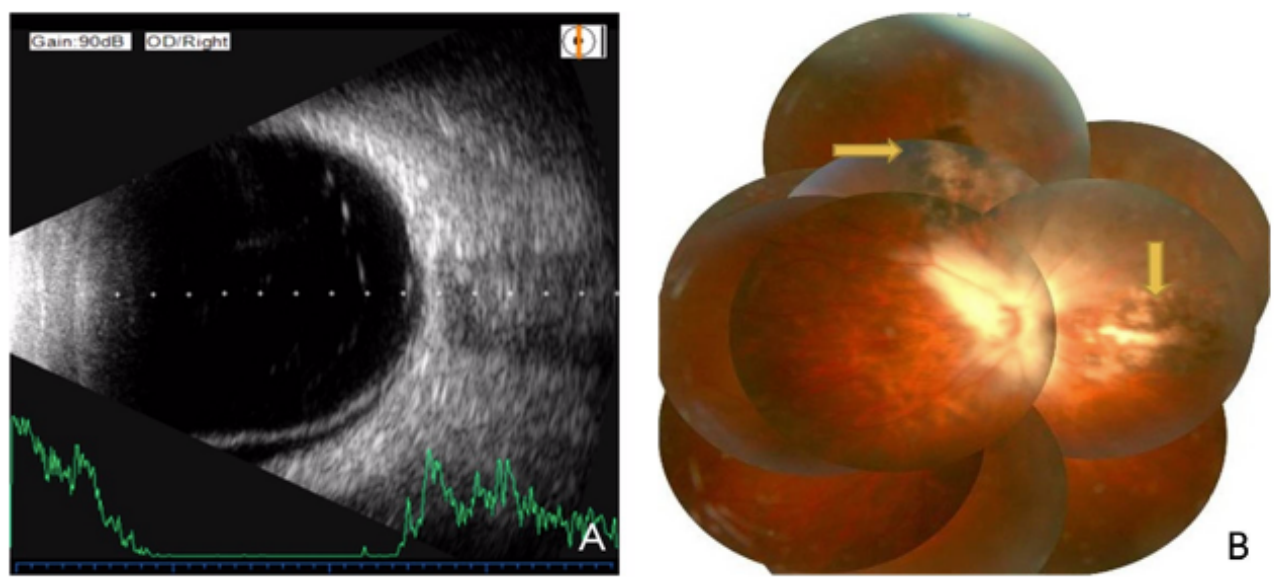

\section{Figure 2}

Images from case 1 female patient, 24 years old, with rhegmatogenous retinal detachment. A. B-scan ultrasonography image showing a strong stripe echo in front of the retina. B. Fundus photograph. Arrows show the myelinated nerve fibres on the nasal side of the optic disc and the site of RPE photocoagulation.

2

\section{Figure 3}

Images from case 14;a 63-year-old male patient with rhegmatogenous retinal detachment, macular hole, and high myopia in the right eye. A. Preoperative retinal detachment B-scan ultrasonography image; B.Intraoperative retinal incision two weeks after the RPE photocoagulation. C. The arrow shows 1 month after surgery. There is visible pigmentation around the incision of the retina; D-E.OCT images 1 month after surgery, the retinal photocoagulation is above, and the thickness of the neurosensory layer is $55 \mu \mathrm{m}$, below. For the RPE pigment photocoagulation, the thickness of the neurosensory layer was $181 \mu \mathrm{m}$.
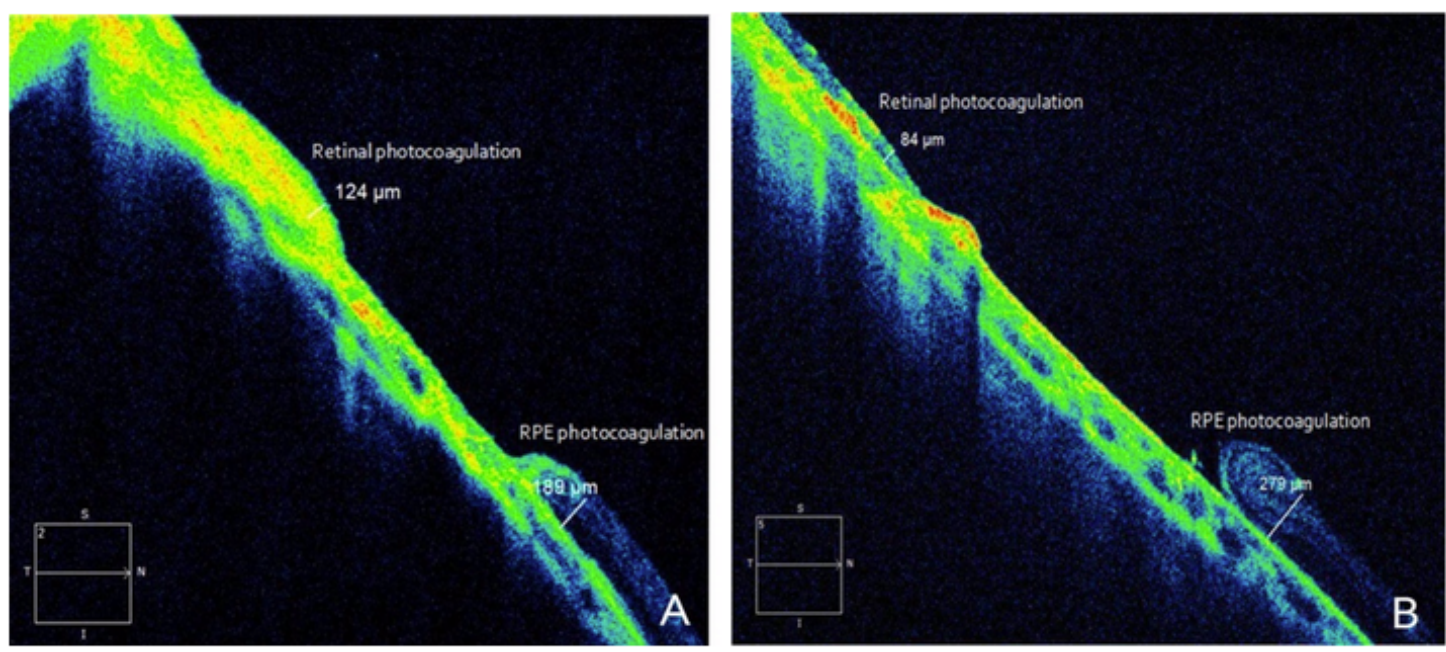

\section{Figure 4}

Image A shows the OCT image of case17 at 1 month after surgery. The thickness of the neurosensory layer of the upper retinal photocoagulation is $124 \mu \mathrm{m}$. The RPE photocoagulation is shown below, and the thickness of the neurosensory layer is $189 \mu \mathrm{m}$. Image B shows the OCT image of case 20 at 1 month after surgery. The thickness of the neurosensorylayer of the upper retinal photocoagulation is $84 \mu \mathrm{m}$. The RPE photocoagulation is shown below, and the thickness of the neurosensory layer is $279 \mu \mathrm{m}$. 